\title{
POLÍTICAS PÚBLICAS, EDUCAÇÃO ESCOLAR E EDUCAÇÃO PROFISSIONAL: APONTAMENTOS SOBRE AS REFORMAS A PARTIR DE 1990
}

\author{
A. M. B. DO N. TAVARES ${ }^{1}$, F. A. A. SANTOS $^{2}$ e L. A. DA S. SANTOS 3
}

Instituto Federal de Educação, Ciência e Tecnologia do Rio Grande do Norte ${ }^{1,2}$, Universidade do Estado do Rio Grande do Norte ${ }^{3}$

andrezza.tavares@ifrn.edu.br ${ }^{1}$

Submetido em 03/10/2018 e aceito em 28/03/2020

DOI: $10.15628 /$ holos.2020.7817

\section{RESUMO}

O presente artigo propõe um estudo bibliográfico sobre Políticas Públicas em Educação no campo da Educação Profissional. Desvela um percurso histórico contraditório e divergente frente aos discursos ideológicos das políticas públicas enquanto espectros visíveis dos projetos societários em disputa. A problemática do trabalho relaciona-se com a conjuntura política, econômica e social em que o mundo está imerso, especialmente, o Brasil que é um Estado de capitalismo neoliberal dependente. Analisaremos o referencial bibliográfico que norteia o pensamento sobre as Políticas Públicas, Educação Escolar e Educação Profissional. Adotamos como procedimento metodológico, o estudo bibliográfico dos teóricos: Arelaro (2000); Cabral Neto (2007), Krawczyk e Vieira (2003);Oliveira e Duarte (2005); Pereira e França (2012); Rodrigues (2007), Ribeiro (2009), bem como, análise documental da Lei de Diretrizes e Bases da Educação Nacional - LDB 9.394/96, lei no 10.172/2001, lei no 11.497/2007, Decreto no 2.208/1997 e a promulgação do Decreto no 5.154/2004. A forma como as políticas públicas no campo da educação vêm sendo concebidas e implementadas tem contribuído para ratificar o pensamento hegemônico e acentuar as desigualdades entre as classes sociais.

PALAVRAS-CHAVE: Políticas Educacionais, Educação Escolar, Educação Profissional.

\section{PUBLIC POLITCS, SCHOOL EDUCATION AND PROFESSIONAL EDUCATION: REFERENCES ON REFORMS AFTER 1990}

\begin{abstract}
This article proposes a bibliographic study on public politics in education in the field of professional education. It reveals a contradictory and divergent historical course in the face of the ideological discourses of public politics as visible spectrum of the corporate projects in dispute. The labor problem is related to the political, economic and social conjuncture in which the world is immersed, especially Brazil, which is a state of dependent neoliberal capitalism. We will analyze the bibliographic reference that guides the thinking about the public politics, school education and professional education. We adopted as methodological procedure,
\end{abstract}

the bibliographical study of the theorists: Arelaro (2000); Cabral Neto (2007), Krawczyk and Vieira (2003); Oliveira and Duarte (2005); Pereira and França (2012); Rodrigues (2007); Ribeiro (2009), as well as documental analysis of the Law of Directives and Bases of National Education LDB 9.394/96, Law no 10.172/2001, Law no 11.497/2007, Decree no 2.208/1997 and the promulgation of Decree $\mathrm{n}$ - 5.154/2004. The way in which public politics in the field of education have been conceived and implemented has contributed to rationalizing hegemonic thinking and accentuating inequalities among social classes.

PALAVRAS-CHAVE: Educational Policies, School Education, Professional Education. 


\section{INTRODUÇÃO}

As reformas das políticas educacionais, a partir da década de 1990, foram se configurando em um cenário mundial de grandes transformações políticas, econômicas e sociais. Este cenário é marcado pela mundialização da economia e pela acumulação flexível do capital, pois tais aspectos contribuíram para redefinição do papel do Estado com a implementação de políticas neoliberais. A ideologia neoliberal, em linhas gerais, apresenta como princípios básicos, a privatização de empresas estatais, a criação de novas regulamentações que diminuem a interferência dos poderes públicos sobre os empreendimentos privados e a descentralização administrativa.

Esses aspectos podem ser confirmados em Höfling (2001), quando afirma que a descentralização é entendida como uma forma de aumentar a eficiência administrativa e de reduzir os custos. Essas medidas têm contribuído para uma maior segmentação da sociedade e historicamente acontece paralelo à consolidação da globalização. Para Noé ( 1937 apud GAMBOA, 2001, p. 125):

A globalização pode ser explicada como um processo no qual se produz uma tendência à homogeneização de valores e com padronização de formas de pensar e de agir. Mas, as tensões e complexidades da era do globalismo implicam dimensões tais como: integração e fragmentação, diversidade e desigualdade. O cenário global não atua só por inclusão, atua também por exclusão; esta nova realidade é múltipla: incorpora regionalismos, nacionalismos e fanatismos religiosos.

As reformas nas políticas educacionais, a partir desse período têm como base o discurso neoliberal e vão sendo desenhadas observando os princípios ditados por organismos internacionais. É nesse contexto que propomos discutir sobre o desenho das políticas educacionais a partir da década de 1990 e como a Educação Profissional foi sendo reorganizada observando os princípios neoliberais. Na reorganização da Educação Profissional, foram instituídas normativas legais as quais foram dando suporte para constituição da Educação Profissional como política pública.

\section{REGULAMENTAÇÃO POR DECRETOS: INDICADOR DE POLÍTICA DEMOCRÁTICA?}

A partir do final do século XIX, em todo o mundo, tem predominado o discurso por meio do qual é pregado a participação mínima do Estado e o mercado como regulador das relações sociais. Tais discursos estão embasados em vários acontecimentos de ordem econômica, social e política que impulsionaram as mudanças estruturais na sociedade como: mundialização da economia, reestruturação da divisão internacional do trabalho, perda de autonomia dos Estados e a sua redefinição no cenário mundial, dentre outros acontecimentos.

Essa reestruturação econômica é ratificada no final do século XX, sobretudo, no Brasil, quando o Estado capitalista não consegue conter a crise do capital dando formas a essa nova organização econômica, utilizando como uma de suas estratégias: a implementação de Políticas Neoliberais. Nesse sentido, Draibe (1993, p. 88) destaca que o neoliberalismo é " antes um discurso e um conjunto de regras práticas de ação (ou de recomendações), particularmente, 
referidas a governos e a reformas do Estado e das suas políticas". Essas recomendações são necessárias, tendo em vista a organização de elementos que compõem a estrutura de uma fase nomeada de acumulação flexível.

Dentre as características dessa fase, destacam-se: a mudança no modelo de produção; as novas relações e acordos comerciais; o aumento da economia informal e a reestruturação do mercado de trabalho. O movimento das características elencadas ampliou a mobilidade do capital e a segmentação da sociedade desencadeando desemprego estrutural e a implementação de contratos de trabalhos mais flexíveis. Como consequência de tal reestruturação, o Estado brasileiro, neste caso, perde autonomia e uma redefinição de seu papel é construída tendo também como consequência a padronização dos aspectos culturais.

Com a reestruturação do papel do Estado, este passou a interferir cada vez menos nas questões sociais. Entretanto, passou a regular as ações do Capital ratificando seu papel de responsável pelo desenvolvimento e regulação social, tendo como base os princípios do mercado. Daí se afirmar que a reestruturação do Estado é excludente, pois o foco de suas ações deixa de ser o social (saúde, educação, transporte, por exemplo), passando, de forma excessiva, a priorizar o econômico.

Essas políticas foram adotadas como referenciais para os programas de desenvolvimento conduzidos pelos organismos internacionais: Fundo Monetário Internacional - FMI, Banco Mundial - BM e Organização de Cooperação e Desenvolvimento Econômico - OCDE. Esses referenciais foram acordados e/ou impostos no Consenso de Washington ${ }^{1}$ que dentre as orientações dadas aos países destacam-se: a disciplina orçamental, a reforma fiscal, a eliminação das barreiras às trocas internacionais, privatização e desregulamentação como enfatizam Krawczyk e Vieira (2003, p. 118):

A reforma consolida um novo modelo de regulação que vem instaurando na organização e governação da educação pública - formas quase mercantis de delegação de poderes e de relação com a demanda educacional, ao adotar o princípio do mercado como indicador das realizações em todas as esferas sociais e também ao ressignificar o conceito de cidadania enquanto consumo.

A reforma do Estado é apresentada como estratégia para ratificar a tese da Ideologia Neoliberal de que não seria o Capitalismo que estaria em crise, mas sim, o Estado. Para amenizar essa crise, o Estado necessitaria ser reformado e é nesse sentido que a reforma atinge todos os setores sociais desencadeando mudanças profundas na tentativa de ajustar de forma estrutural

\footnotetext{
${ }^{1} \mathrm{O}$ consenso de Washington formou-se a partir da crise do consenso Keynesiano(Hicks - 1974 e Blcaney - 1985 e da correspondente crise da teoria do desenvolvimento econômico elaborada nos anos 40 e 50 (Hirschman 1979). Por outro lado, essa perspectiva é influenciada pelo surgimento, e afirmação como tendência dominante, de uma nova direita, neoliberal, a partir das contribuições da escola austríaca (Hayek, Von Mises), dos monetaristas (Friedman, Phelps, Johnson), dos novos clássicos relacionados com as expectativas racionais (Lucas e Sargent) e da escola da escolha pública (Buchanan, Olson, Tullock, Niskanen). Essas Visões teóricas, temperadas por um certo grau de pragmatismo, próprio dos economistas que trabalham nas grandes burocracias internacionais, é partilhada pelas agências multilaterias em Washington, o Tesouro, o FED, e o Departamento de Estado dos Estados Unidos, os ministério das finanças dos demais países dos G-7 e os presidentes dos vintes maiores bancos internacionais constantemente ouvidos em Washington. Esta abordagem dominante em Washington exerce poderosa influência sobre os governos e as elites da América Latina (PEREIRA, 1991, P. 5).
} 
uma maior regulação baseada nos princípios do neoliberalismo. Krawczyk, Campos e Haddad (2000) destacam também três lemas das políticas públicas na era dos ajustes estruturais: focalizar em políticas compensatórias, descentralizar as operações estratégicas e privatizar. Assim, podemos afirmar que as ações do discurso neoliberal são estratégicas no sentido de contribuir para o aumento das desigualdades sociais.

É nesse contexto, que na década de 1990, iniciou-se o movimento de reforma na educação, a partir de compromisso firmado na Conferência Mundial sobre Educação para Todos em Jomtien - Tailândia ${ }^{2}$. Compromisso firmado também pelo Brasil, tendo em vista que um dos critérios para recebimento dos empréstimos internacionais seria a aceitação das deliberações acordadas ou impostas na Conferência. Para Pereira e Santos (2008), nessa perspectiva, o Projeto de Política Educacional no Brasil se materializa através de dois movimentos: da contradição entre Estado mínimo e do Estado máximo apresentado nos processos de centralização/descentralização e no conteúdo do projeto de descentralização. Krawczyk, Campos e Haddad (2000) assinalam que as ações dessa reforma programaram um novo modelo de organização e gestão da educação pública que foi materializado nas normativas legais da educação e impostas através de documentos e programas implementados pelos diversos governos.

A discussão, a organização e a elaboração destas normativas legais iniciam seus trabalhos, a partir do final da década de 1980, com o surgimento do Projeto de Lei de Diretrizes e Bases da Educação Nacional - LDBEn 9.394/1996. As discussões giram em torno de dois projetos, um que teve a preocupação de consultar os diferentes segmentos que estavam envolvidos com a educação e o outro que apresentava a organização da educação baseada nos princípios que foram deliberados na Conferência de Educação para Todos. Nessa conjuntura, são organizados os grupos de trabalho para discussão e elaboração do Plano Nacional de Educação para Todos e nesse sentido,

Deixa claro que o governo brasileiro começa a aceitar, em Educação, compromissos e orientações nos termos das exigências das agências de financiamento internacionais, ainda que o termo de compromisso firmado entre as entidades e o governo tenha sido expresso numa linguagem progressista, em que as palavras participação, descentralização, autonomia, discussão e gestão coletiva são freqüentes (ARELARO, 2000, p. 98).

Observa-se que o teor das normativas legais que estão sendo elaboradas apresenta nas entrelinhas o discurso de que o Estado deve se preocupar menos com o social e mais com os princípios do mercado ratificando, dessa maneira, a ideologia neoliberal. Nessa perspectiva Hypolito (2010) salienta que essa reforma deve ser compreendida muito mais como uma política de regulação de Estado do que de uma política educacional de governo.

\footnotetext{
${ }^{2}$ A Conferência Mundial de Educação para todos aconteceu em março de 1.990 em Jomtien - Tailândia. Nesta conferência foi aprovado o Plano de Ação para satisfazer as necessidades básicas de aprendizagem. Esse Plano de Ação foi concebido como uma referência e um guia para governos, organismos internacionais, instituições de cooperação bilateral, organizações não-governamentais (ONGs), e todos aqueles comprometidos com a meta da educação para todos.Tal plano compreende três grandes níveis de ação conjunta: (i) ação direta em cada país; (ii) cooperação entre grupos de países que compartilhem certas características e interesses; e (iii) cooperação multilateral e bilateral na comunidade mundial.
} 
É nesse processo de discussões que a LDB no. 9.394/96 é aprovada. Em seu texto, é atribuído à educação um papel de qualificação para o trabalho, isto é, a função da educação seria capacitar profissionalmente o indivíduo para atuar no mercado de trabalho. Para o governo, es sa seria uma forma de sanar os problemas da crise de emprego e da própria exclusão social, porém, isso é apenas mais uma falácia, pois o governo desconsidera toda a conjuntura estrutural da sociedade brasileira na análise desse problema e leva em conta, apenas, as recomendações dos organismos internacionais.

Também é necessário chamar atenção que ao tempo que o governo de Fernando Henrique Cardoso tem, sobretudo, o discurso de que a preparação para o trabalho seria uma forma de sanar problemas de emprego e que a reforma seria um meio de modernizar a educação, de acordo com os avanços tecnológicos e de organização de trabalho (RAMOS, 2002), a Educação Profissional é discutida na supracitada LDB como uma modalidade de ensino desobrigando o governo de sua oferta e cedendo espaço para que a iniciativa privada o oferte.

Nesse direcionamento, percebe-se o descaso do governo com as questões educacionais, principalmente, com a Educação Profissional que vem apresentada no documento legal citado, não como uma Política Pública, mas como um programa de governo que ratifica a segmentação entre a formação geral e a formação técnica. Segundo a ótica neoliberal, a formação geral deve ser ofertada com exclusividade pela Educação básica.

O desenho da política de Educação Profissional começa a ser esboçada a partir de reformas baseadas em um conjunto de normativas legais. Observa-se que o interesse pela reforma não reside em ofertar uma educação universal e única para todas as classes sociais, mas desagregar. Pereira e França (2012, p. 224) reforçam, em relação a essa desagregação ao afirmarem que a Reforma

Resultou no ensino propedêutico direcionado para os extratos sociais economicamente providos e em uma educação profissional para atender a maioria dos sujeitos que, precocemente, ingressa no mercado de trabalho segregador, por questão de sobrevivência.

Tal aspecto foi ratificado com a instituição do Decreto 2.208/1997 que traz um conjunto de reformas para serem implementadas na modalidade de Educação Profissional, dentre elas, destacando-se: separação entre o ensino médio e o ensino técnico, reforma curricular com a introdução da noção de competência, criação do Programa de Expansão da Educação Profissional - PROEP, redução da carga horária dos cursos, instituição da Portaria no 646/19973. Assim, é consenso entre os teóricos tais como Ramos (2002), Frigotto e Ciavatta (2005), dentre outros autores de que a instituição deste Decreto trouxe muitos prejuízos à consolidação da Educação Profissional enquanto política pública, como também a exclusão das camadas populares que ascendiam à continuação de estudos, contribuindo assim com o aumento das desigualdades entre as classes sociais.

\footnotetext{
${ }^{3}$ A Portaria no 646/1.997 foi instituída no governo de Fernando Henrique Cardoso que dispõe sobre a redução da oferta de Ensino Médio dos CEFETs e das ETF para 50\%. Para Pereira e França (2012) a Portaria limitoua autonomia das instituições federais comprometendo a oferta da educação profissional e subordinando-as ao mercado de trabalho.
} 


\section{O DECRETO № 5.154/2004 E A REINTEGRAÇÃO ENTRE O ENSINO PROPEDÊUTICO E A FORMAÇÃO TÉCNICO-PROFISSIONALIZANTE}

A partir do final do ano de 2002, a discussão sobre a relação entre Ensino Médio e Educação Profissional é retomada culminando com a discussão sobre a revogação do Decreto no 2.208/1997 e a promulgação do Decreto no 5.154/2004. Este último decreto tinha como objetivo, a possibilidade de integração do Ensino Médio com a Educação Profissional e coadunava com o proposto por Frigotto, Ciavatta e Ramos (2005, p. 43): “O Ensino Médio integrado ao Ensino Técnico, sob uma base unitária de formação geral, é uma condição necessária para se fazer a travessia para uma nova realidade".

O Decreto n․ 5.154/2004 abre espaço para que a integração entre Ensino Médio e Educação Profissional aconteça.Entretanto é necessário um reordenamento da estrutura do sistema de educação, especificamente, da Educação Profissional. Tal reordenamento passa pela reestruturação das ações relacionadas à parte pedagógica, adequação da estrutura física e perceber a Educação Profissional como Política Pública, para que haja a articulação entre as instituições estaduais e federais, dentre outros aspectos.

Com o Decreto no. 5.154/2004, novos instrumentos legais foram instituídos para oferecer suporte para implementação do Decreto como: criação do Fundo de Manutenção e Desenvolvimento da Educação Básica e de Valorização dos Profissionais da Educação - FUNDEB, Lei no 11.180/2005/ Programa Escola de Fábrica/ Lei no 11.892/2008 - Rede Federal de Educação Profissional, Científica e Tecnológica. Mesmo com as normativas legais e programas implementados em termos de políticas públicas sobre a concepção de integração entre Ensino Médio e Educação Profissional ainda se carece de informações basilares sobre suas bases conceituais. Como já foi afirmado, a integração é a "travessia" para a politecnia, e esta está associada à ideia de omnilateralidade, pois,

\footnotetext{
Implica considerar que o ser humano deve ser integralmente desenvolvido em suas potencialidades, por meio de um processo educativo que privilegie a formação científica, a política e a estética. Assim, tal concepção compreende todas as dimensões do ser humano, para se alcançar o desenvolvimento integral do trabalhador, o que não é viável para os interesses dos representantes do capital. Diante desse embate, fazse necessária a implementação de um projeto pedagógico descomprometido com as determinações exclusivas do capital (PEREIRA \& FRANÇA, 2012, p. 233).
}

Mesmo com todo aparato legal, ainda falta muito para que a integração entre Ensino Médio e Educação Profissional de fato aconteça. Além das normativas legais, muitas pesquisas já estão sendo desenvolvidas e contribuem para o entendimento e amadurecimento da temática. Neste sentido de integração do Ensino Médio com a Educação Profissional, a Lei 11.741/08 altera a LDB n‥ 9.394/1996 enfatizando as formas de articulação da Educação Profissional com o Ensino Médio. No discurso sobre integração, falta ainda os governos assumirem a Educação Profissional como política pública, isto é, construírem ações partindo de bases concretas pautadas em representações sociais e culturais de uma realidade local. 
É nesse contexto de implementação de ações voltada para Educação Profissional integrada, que no ano de 2011 é aprovado o Parecer CNE/CEB no 5/2011 que estabelecia as Diretrizes Curriculares Nacionais para o Ensino Médio e orientava os sistemas de ensino (entidades responsáveis pela gestão escolar em todas as esferas - federal, estadual e municipal) e as escolas sobre a organização curricular e todas as formas e modalidades de Ensino médio. Desse modo, o documento traz:

Art. 10 Define as Diretrizes Curriculares Nacionais para o Ensino Médio, a serem observadas na organização curricular pelos sistemas de ensino e suas unidades escolares.

Parágrafo único Estas Diretrizes aplicam-se a todas as formas e modalidades de Ensino Médio, complementadas, quando necessário, por Diretrizes próprias.

Art. 20 As Diretrizes Curriculares Nacionais para o Ensino Médio articulam-se com as Diretrizes Curriculares Nacionais Gerais para a Educação Básica e reúnem princípios, fundamentos e procedimentos definidos pelo Conselho Nacional de Educação, para orientar as políticas públicas educacionais da União, dos Estados, do Distrito Federal e dos Municípios na elaboração, planejamento, implementação e avaliação das propostas curriculares das unidades escolares públicas e particulares que oferecem o Ensino Médio. (PARECER CNE/CEB №: 5/2011)

Todavia, faz-se necessária uma análise comparativa entre o que está no texto do documento e o que está sendo implementado no intuito de identificar os discursos e situar os programas vinculados à política em desenvolvimento. É nesse sentido, que identificamos como a política curricular de Educação Profissional vai sendo desenhada e a que tipo de sujeito ela se propõe desenvolver.

Desde o Decreto no 2.208/1997 já estava claro em seu texto a emergência da noção de competência subjacente à política curricular. A introdução desse termo deu uma nova configuração ao desenho curricular, tendo em vista que a partir da elaboração das competências foram sendo organizadas as áreas e o perfil profissional de cada área, visto que "[...] será o mercado de trabalho o principal regulador do exercício profissional, com populações de formandos encontrando severas barreiras ao exercício da atividade para a qual teriam sido formados" (RAMOS, 2002, p. 404).

Como as competências são mutáveis, a inserção do trabalhador no mercado de trabalho não garante a sua permanência, aspecto que dificulta as relações coletivas e o sentimento de pertencimento a uma categoria. A concepção de currículo, presente no Decreto no 2.208/1997, tem como base, a prática e sua fundamentação teórica no Construtivismo. Essa fundamentação teórica enfraquece e/ou corrobora para uma prática dissociada das questões estruturais e política da sociedade e ratifica o discurso construído no imaginário social sobre a Educação Profissional. Nessa perspectiva,

[...] a construção das matrizes curriculares da educação profissional faz-se necessária aos representantes do capital que empregam na legislação, de forma populista o termo cidadania envolto em uma política de Estado que defende o ideário pedagógico unilateral do mercado, que contrapõe à crítica, à autonomia e à criatividade, elementos relevantes para o exercício da cidadania, da participação política, em função da transformação da sociedade (PEREIRA \& FRANÇA, 2012, p. 228). 
Com a revogação do Decreto no 2208/1997 e a promulgação do Decreto no 5154/2004, a concepção de currículo centra-se no trabalho como princípio educativo no sentido de abranger todas as dimensões humanas, conforme afirmam Ciavatta, Frigotto e Ramos (2005, p. 20):

\begin{abstract}
O trabalho como princípio educativo tem duas dimensões: a primeira, ontológica ou ontocriativa, que por meio do trabalho, o ser humano em relação com a natureza produz conhecimento, este faz com que as condições da natureza sejam alteradas, alterando assim, sua própria vida, a segunda, a visão histórica que o trabalho experimenta diversas formas, desde os primitivos, o trabalho servil até chega no trabalhador assalariado sob a égide da lógica capitalista.
\end{abstract}

O Parecer CNE/CEB no 5 de 2011, institui as Diretrizes Nacionais para o Ensino Médio possibilitando discutir quem é o sujeito do Ensino Médio e em que lugar este sujeito está. Nessa perspectiva, a concepção de currículo integrado em que o sujeito percebe a realidade como um todo concreto precisa ser discutida e refletida para ser implementada, de fato, nas instituições escolares.

O currículo integrado está relacionado com a totalidade da formação do ser humano, uma vez que, como formação humana politécnica, o que se busca é garantir ao adolescente, ao jovem e ao adulto trabalhador o direito a uma formação completa para a leitura do mundo e para a atuação como cidadão pertencente a um país, integrado dignamente à sua sociedade política. Formação que, neste sentido, supõe a compreensão das relações sociais subjacentes a todos os fenômenos.

Dessa maneira, o Currículo Integrado é uma tentativa de possibilidade dos estudantes terem acesso aos conhecimentos científicos e culturais da humanidade, aos espaços para o desenvolvimento da experimentação e das práticas de estudo e investigação. Para tanto, é necessário uma atitude docente diferenciada que passa, necessariamente, pelo processo de formação inicial e continuada subjacente à Política Pública de Educação Profissional. Daí se afirmar que o ensino pautado em um Currículo Integrado deve se diferenciar dos projetos vinculados aos interesses, exclusivamente, de mercado. É um ensino que pretende formar um profissional crítico capaz de refletir sobre sua condição social e participar das lutas em favor dos interesses da coletividade.

Também pode ser apontada como uma das características do Currículo Integrado, a formação do ser humano com a capacidade de entender todas as formas de relações sociais, políticas e econômicas. Além de transformar a sua realidade e a formação de sujeitos autônomos, tal perspectiva visa romper com a fragmentação e a neutralidade que se prega com relação ao currículo, contribuindo assim, para uma formação em que se vislumbre a emancipação dos estudantes.

\title{
4 CONSIDERAÇÕES FINAIS
}

Diante do exposto, a Política Pública de Educação Profissional vem se consolidando e construindo uma identidade própria. Em seu percurso histórico, apresentou alguns avanços, dentre os quais, destacamos a concepção de Currículo Integrado. Essa discussão emerge na 
década de 1990 e foi somente regulamentada por meio do Decreto no 5.154/2004 que apontava para uma perspectiva de uma Educação Integrada.

Ao discutirmos Currículo Integrado precisamos pensar em uma educação que vislumbre o homem como um ser histórico, social e concreto. Nessa perspectiva, a educação deverá contribuir para o desenvolvimento omnilateral do ser humano e proporcionar aos estudantes também a compreensão dos aspectos sociais, políticos, econômicos e culturais, tendo o trabalho como princípio educativo. Assim, a ênfase do trabalho como princípio educativo relaciona-se à compreensão de todo o processo de existência humana. Em virtude disso, afirma-se que a instituição do Currículo Integrado no processo de ensino significa um passo na organização e constituição de uma educação de qualidade, e consequentemente, de uma sociedade mais humana.

A visão cristalizada de que a Educação Profissional deve formar, exclusivamente, para o trabalho, é uma visão ultrapassada e que vem sendo substituída, paulatinamente, pelo discurso da integração entre Ensino Médio e Educação Profissional.

Contudo, para que aconteça essa integração de forma plena é necessário que ocorra uma interação concebida a partir de diálogos entre Estado e a sociedade com vistas ao conhecimento da real importância social da implementação dessa política, visando aos ganhos sociais advindos dela.

Dessa forma, acredita-se que, a Educação Profissional integrada ao Ensino Médio, possibilitará a construção, a longo prazo, de uma sociedade mais justa, pois, os sujeitos receberão uma preparação intelectual e profissional para agirem em uma sociedade, mesmo que a tônica seja a do mercado, pois dessa maneira é possível construir uma identidade em que o ser humano será sempre o sujeito dos processos sociais.

Por fim, nota-se que é preciso entender a finalidade do Ensino Médio para além dos exames de seleção (ENEM) ou mercado de trabalho, mas sim na direção das necessidades materiais e conceituais dos seus estudantes. Isso significa pensar o homem, como referência para as práticas formativas, em oposição à ditadura do mercado.

\section{REFERÊNCIAS}

ARELARO, L. R. G. (2000). Resistência e Submissão: a reforma educacional na década de 1990 In: KRAWCZYK, N., CAMPOS, M. M.; HADDAD, S.(Orgs.) O cenário educacional latinoamericano no limiar do século XXI: reformas em debate. Campinas, SP: Autores Associados - Coleção Educação Contemporânea.

BRASIL. PARECER CNE/CEB No: 5/2011 de 24 de novembro de 2012. Institui as Diretrizes Nacionais para o Ensino Médio, publicado no Diário Oficial da União, Brasília, DF, 2012.

BRASIL. Lei no 11.741, de 16 de julho de 2008. Altera dispositivos da Lei n. 9.394, de 20 de dezembro de 1996. Disponível em: <http://www.legislação.planalto.gov.br>. Acesso em: 26 setembro 2013. 
BRASIL.Lei Federal $n^{\circ}$ 9.394/96, de 20 de dezembro de 1996. Lei das Diretrizes e Bases da Educação Nacional (LDBEN). Estabelece as Diretrizes e Bases da Educação Nacional. Educação Profissional: legislação básica. 5.ed. Brasília: MEC, 2001.

BRASIL.Decreto no 2.208/97 de 17 de abril de 1997. Regulamenta o parágrafo 2ㅇ do art. 36 e os artigos 39 a 42 da Lei no 9394, de 20 de dezembro de 1996, que estabelece as diretrizes e bases da educação nacional. Diário Oficial da União, Brasília, DF, 18 de abr. 1997.

BRASIL. Decreto no 5.154, de 23 de julho de 2004. Regulamenta o §2‥ do art.36 e os arts. 36 a 42 da lei 9.394, de 20 de dezembro de 1996, que estabelece as diretrizes e bases da educação nacional e dá outras providências.

BRASIL.Lei no 11.494 (2007). Regulamenta o Fundo de Manutenção e Desenvolvimento da Educação Básica e de Valorização dos Profissionais da Educação - FUNDEB. www.planalto.gov.br, Acesso em 18 de ago 2007.

CABRAL NETO, A.; RODRIGUES, J. (2007). Reformas Educacionais na América Latina: cenários, proposições e resultados In: Pontos e Contrapontos da política educacional: uma leitura contextualizada de iniciativas governamentais/ Organizadores: Antônio Cabral Neto - [et ali] - Brasília: Líber Livro Editora.

CONFERÊNCIA DE JOMTIEN TAILÂNDIA, (1990), Tailândia. Declaração mundial sobre educação. para todos. Disponível em: <http://www.unicef.org/brazil/pt/resources_10230.htm>. Acesso em: 06 jan. 2013.

DRAIBE, S. (1993). As políticas sociais e o neoliberalismo: reflexões suscitadas pelas experiências latino-americanas. Revista USP, n. 17, p. 86 - 101, mar/maio.

FRIGOTTO, G. CIAVATTA, M. RAMOS, M. (Org). (2005). Ensino Médio Integrado: concepções e contradições. São Paulo: Cortez.

GAMBOA, S. S. (2001). A globalização e os desafios da Educação no limiar do novo século. In: LOMBARDI, José Claudinei. (Org.). Globalização, Pós-modernidade e Educação: história, filosofia e temas transversais. Campinas: Associados.

HYPOLITO, Á M. (2010). Políticas Curriculares, Estado e Regulação. Educação e Sociedade, v. 31 , n. 113 , p. $1337-1354$. Out. - dez.

HÖFLING, E. M. (2001). Estado e Políticas (públicas) Sociais. Caderno CEDES, vol. 21, n. 55, Campinas novembro.

KRAWCZYK, N. R.; VIEIRA, V. L. (2003). Estudos Comparados nas análises sobre política educacional da América Latina. In: KRAWCZYK, Nora R.; WANDERLEY, Luiz Eduardo (Orgs.) América Latina - Estado e Reformas numa perspectiva comparada. São Paulo, Cortez.

KRAWCZYK, Nora R; CAMPOS, Maria Malta; HADDAD, Sérgio (orgs.). (2000). O cenário educacional. latino-americano no limiar do século XXI: reformas em debate - Campinas, SP: Autores Associados - (Coleção Educação Contemporânea). 
OLIVEIRA, D; DUARTE, A. (2005). Política educacional como política social: uma nova regulação da pobreza. Disponível em: https://periodicos.ufsc.br/index.php/perspectiva/article/view/9755/8987 . Acesso: setembro 2016.

PEREIRA, L. C. B. (1991). A crise da América Latina: consenso de Washington ou crise fiscal? Rev. Pesquisa e Planejamento Econômico, 21, n. 1, p. 3-23, abr.

PEREIRA, M. Z. da C.; SANTOS, E. da S. (2008). Globalização e Políticas Curriculares no Brasil de 1985 a 2006: entre os processos de regulação e emancipação. Revista Espaço do Currículo, 1, n. 1 p. 65-99. mar-set.

PEREIRA, U. Á.; FRANÇA, M. (2012). Políticas de Educação Profissional e de Ensino Médio no Brasil (1998-2008) In: CASTRO, Alda Maria Duarte Araújo; FRANÇA, Magna (Orgs.). Política Educacional: Contextos e perspectivas da educação brasileira. Brasília: Líber Livro.

RAMOS, M. N. (2002). A educação profissional pela pedagogia das competências e a superfície dos documentos oficiais. Revista Educação e Sociedade, Campinas, 23, n. 80, p. 401-422, set.

RIBEIRO, J. L. L. S. (2009). A avaliação como uma política pública: aspectos da implementação do SINAES. In: LORDÊLO, J. A. C.; DAZZANI, M. V. (Org.). Avaliação educacional: desatando e reatando nós. Salvador: EDUFBA. p. 57-84. Disponível em: <http://static.scielo.org/scielobooks/wd/pdf/ lorde- lo-9788523209315.pdf>. Acesso em: 10 dez. 2013.

RODRIGUES, W. C. (2007). Metodologia Científica. Disponível em: <http://unisc.br/portal/upload/com_arquivo/metodologia_cientifica.pdf>. Acesso em: 18 ago.2015. 